\title{
Facilitated Transport of Cd (II) And Pb(II) Through Polymer Inclusion Membranes with Di-(2-Ethylhexyl) Phosphoric Acid as Carrier in Aqueous Solution
}

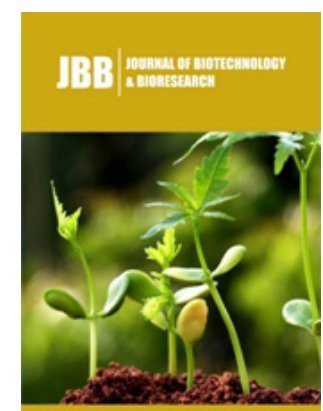

*Corresponding author: Arous 0 , Laboratory of Hydrometallurgy and Inorganic Molecular Chemistry, Faculty of Chemistry, University of Sciences and Technology Houari Boumediene (USTHB) PO Box 32 El Alia Babezzouar Algiers Faculty Algeria

Submission: 望 November 4, 2019

Published: 監 March 11, 2020

Volume 2 - Issue 3

How to cite this article: Briki $\mathrm{H}$ Abdellaoui N, Metref F, Akretche DE, Arous. Facilitated Transport of Cd (II) And Pb(II) Through Polymer Inclusion Membranes with Di-(2-Ethylhexyl) Phosphoric Acid as Carrier in Aqueous Solution. J Biotech Biores.2(3). JBB.000539.2020.

Copyright@ Arous 0, This article is distributed under the terms of the Creative Commons Attribution 4.0 International License, which permits unrestricted use and redistribution provided that the original author and source are credited.

\section{Briki $\mathrm{H}^{1}$, Abdellaoui $\mathrm{N}^{1}$, Metref $\mathrm{F}^{1}$, Akretche $\mathrm{DE}^{2}$ and Arous $\mathrm{O}^{2 *}$}

${ }^{1}$ Laboratory of Polymer Materials, Faculty of chemistry, University of Sciences and Technology Houari Boumediene (USTHB) PO Box 32 El Alia Babezzouar Algiers Algeria

${ }^{2}$ Laboratory of Hydrometallurgy and Inorganic Molecular Chemistry, Faculty of Chemistry, University of Sciences and Technology Houari Boumediene (USTHB) PO Box 32 El Alia Babezzouar Algiers Faculty Algeria

\begin{abstract}
Polymer inclusion membranes used for selective transport and separation of metallic ions have emerged in recent times. Their expansion depends on the method of preparation and the study of their structure. In this paper, an improvement of a novel category of membrane for performing toxic ions elimination was reported. Different membranes were synthesized using a mixture of polymers: polysulfone (PSu) and cellulose triacetate (CTA), Dioctylphtalate (DOP) was used as a plasticizer and Di-(2-ethylhexyl) phosphoric acid (D2EHPA) was incorporated into the polymers as carrier to increase specific interactions between the different components. The membranes (polymers- plasticizer-carrier) were synthesized using a new method and characterized by various techniques including Fourier Transform Infrared (FTIR) spectroscopy, X-Ray Diffraction (XRD), Thermogravimetric Analysis (TGA), Scanning Electron Microscopy (SEM) and contact angle. As the plasticizers' molecules were hydrophobic; their location at the surface of the modified polymeric membranes should modify the contact angle. Overall, our results showed that the addition of plasticizer with two polymers resulted in a homogeneous and hydrophobic membranes. A study of transport of $\mathrm{Pb}(\mathrm{II})$ and $\mathrm{Cd}(\mathrm{II})$ using synthesized membranes was studied. Dialysis experiments of lead and cadmium ions across a polymer inclusion membrane have proved a good performance.
\end{abstract}

Keywords: Polymers; Plasticizer; Organic membranes; Heavy metals; Water purification

\section{Introduction}

Recovery and reuse of metal ions from industrial waste-streams can be of large help for environmental pollution control and for cost reduction. Membrane-based separations offer a greater potential for practical application since loss of the macrocyclic metal ion carrier from the membrane into contacting source and receiving aqueous phases may be very low. However, the use of membrane technologies is constrained to systems with appropriate chemical and mechanical stabilities and useful lifetimes [1-5]. The extensive use of polymers in medical and pharmaceutical applications including particularly packaging, medical devices, drug carriers and coatings has caused a substantial demand for the proper plasticizers. Although there are many plasticizers used in the chemical industry, only a few of them have been approved for pharmaceutical applications. The natural-based plasticizers characterized by low toxicity and low migration are required nowadays not only for pharmaceutical and medical applications. In this respect, most of traditional plasticizers are not applicable in this area. The primary role of all plasticizers as low molecular weight non-volatile additives is to improve the flexibility and processability of polymers by lowering the second order transition temperature (glass transition temperature, $\mathrm{Tg}$ ) [6]. The extent of Tg reduction in the presence of a plasticizer can be used as a parameter to assess the plasticization efficiency [7]. When incorporated into a polymeric material, a plasticizer improves the workability and flexibility of the polymer by increasing the intermolecular separation of the polymer molecules. Effort has been directed towards the development of such membranes and some promising materials and designs have been described. Metal ion separations using plasticized cellulose triacetate (CTA) membranes currently are receiving considerable attention [8-12]. In order to reduce the amounts of reactants and energy needed for separation and to decrease the environmental and economic 
impact of solvent extraction separations, several membrane-based separation techniques have been proposed in the past 30 years.

The complexing agents are used to enhance the transport of solutes across the membrane, and if the carrier binds preferentially to one solute over others, the transport selectivity for the preferred solute can be enhanced. Carriers are found in different types: basic (e.g., quaternary amines ) [13], acidic and chelating (e.g., sulfonic acids) [14], neutral (e.g., phosphoric acid esters) [15], macrocyclic and macromolecular (e.g., imidazole azothiacrown ethers) [16]. For the transport of alkali metals (e.g., $\mathrm{K}^{+}$), macrocyclic and macromolecular crown ethers are commonly used as carriers [17]. They have a specific host-guest complexation behavior which allows the transport of the target ion across the PIM. This phenomenon is termed facilitated transport and has been the subject of numerous articles [18-26]. Recently, several acyclic and macrocyclic ligands with selectivity for $\mathrm{Pb}(\mathrm{II})$ have been reported [27-29]. The coordination properties of $\mathrm{Pb}^{2+}$ have been reviewed by Parr J [30]. From the relationship between ligand structure and the $\mathrm{Pb}^{2+}$ coordination behaviour of several mixed nitrogen/oxygen/ sulphur donor macrocyclic compounds, a preference of $\mathrm{Pb}^{2+}$ for nitrogen donor atoms is clear.

In this work, we have synthesized a novel class of PIM using two polymers: CTA and PSu. All synthesized membranes are plasticized by dioctylphtalate (DOP) and modified by Di-(2-ethylhexyl) phosphoric acid (D2EHPA) carrier incorporation that are selectively permeable to lead and cadmium ions. The different membranes were characterized using physical and chemical techniques as well as Fourier Transform Infra-Red (FTIR), Thermogravimetric analysis (TGA), X-ray diffraction (XRD) and Scanning electron microscopy (SEM). Transport of lead and cadmium in aqueous solution has been studied using these systems and the results were compared. The influence of the membrane nature has been studied using some supports of different physical characteristics (porosity, thickness, hydrophobia).

\section{Experimental}

\section{Materials}

All chemicals (highest purity grade) were used as received without any further purification. Chloroform $\left(\mathrm{CHCl}_{3}\right)(\mathrm{GC} \geq 99 \%)$, tetra hydro furane (THF) $(99,99 \%)$, pure cellulose triacetate (CTA), polysulfone (PSu) and Di-(2-ethylhexyl) phosphoric acid (D2EHPA) were purchased from Fluka, dioctylphtalate (DOP), $\mathrm{Pb}\left(\mathrm{NO}_{3}\right)_{2}$ and $\mathrm{Cd}\left(\mathrm{NO}_{3}\right)_{2}$ were obtained from Carlo Erba. Aqueous solutions were prepared ultrapure water obtained by a Millipore purification unit (Millipore B.V., Amsterdam, The Netherlands).

\section{Technical characterization}

FTIR spectra of different membranes are recorded using Perkin Elmer spectrophotometer (Spectrum One model) in the range of $400-4000 \mathrm{~cm}^{-1}$ with a resolution of $2 \mathrm{~cm}^{-1}$ and total of 32 scans were accumulated for each spectrum along with the background. The surface morphologies of the synthesized membranes were observed using SEM imaging via a Philips Scanning Electron
Microscope XL30 FEG (Netherlands) with a voltage of 10keV. Each sample was coated with platinum after being dried in a vacuum oven at low temperature. The contact angle measurements were given as the tangent angle of the drop with the membrane surface. Water contact angles were recorded with an OCA20 Data-physics Instruments with a syringe to control the droplet size. The average of five arbitrarily selected locations for each sample represents the reported contact angle measurements. Conventional TGA was performed using $10 \mathrm{mg}$ of membranes using TA instruments TGA-Q 500 thermogravimeter under nitrogen atmosphere with a heating rate of $10^{\circ} \mathrm{C} / \mathrm{min}$.

\section{Polymeric membranes preparation}

Polymeric membranes were prepared using the modified procedure described by Sugiura M [31-33]. In this method, $0.2 \mathrm{~g}$ of cellulose triacetate (CTA) were dissolved in $30 \mathrm{~mL}$ of chloroform $(\mathrm{CHCl} 3)$ and $0.2 \mathrm{~g}$ of polysulfone (PSu) were separately dissolved in $30 \mathrm{~mL}$ of tetrahydrofuran (THF) and stirred for $4 \mathrm{~h}$. Then, $0.1 \mathrm{~mL}$ of DOP (as plasticizer) and $0.1 \mathrm{~mL}$ of D2EHPA (as carrier) were added respectively in the first solution under vigorous stirring during $2 \mathrm{~h}$. After a homogenous solution was obtained, the mixture was transferred to circular glass containers and the solvent was slowly and completely evaporated in an oven at $50{ }^{\circ} \mathrm{C}$. The formed membrane was detached from the glass using water. Then, the membrane was placed between two compartments of the transport cell, with an active area of $9.61 \mathrm{~cm}^{2}$. Four different membranes were prepared: (PSu + DOP), (CTA + DOP), (PSu + CTA + DOP) and (PSu + CTA + DOP + D2EHPA).

\section{Dialysis experiments}

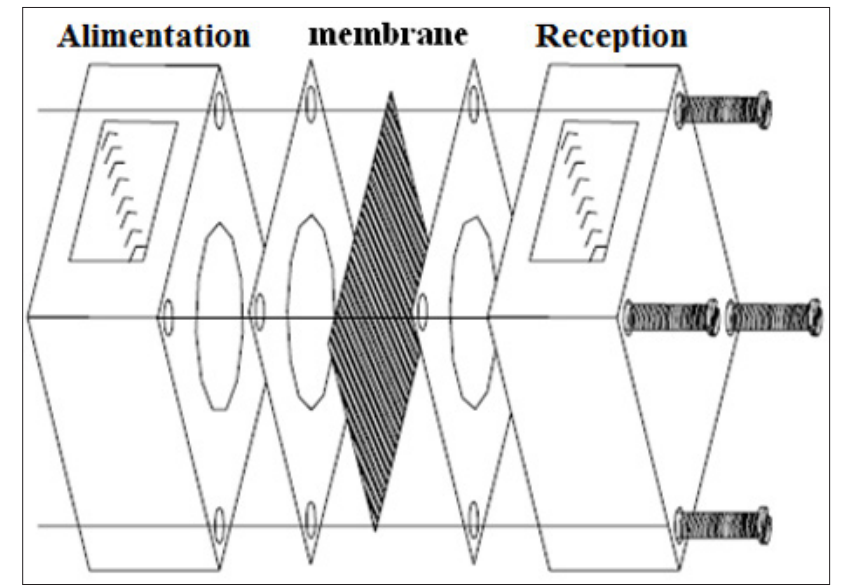

Figure 1: Transport cell used in the dialysis experiments.

Transport experiments were carried out in a permeation cell made of Teflon in which the membrane film was tightly clamped between two cell compartments (Figure 1). Both the source and receiving aqueous phases $(100 \mathrm{~mL}$ each) were stirred at $800 \mathrm{rpm}$ using a multi-point magnetic stirrer (Wise-Stir MS-MP8 Model, made by DAIHAN Scientific Co. Ltd.). The metal concentrations were determined by samplings at different time interval aliquots $(0.5 \mathrm{~mL})$ from both the feed and strip solutions and analyzed 
using the atomic absorption spectroscopy technique (AAS) with a Perkin-Elmer AAnalyst 700 model. The membrane surface area was $9.61 \mathrm{~cm}^{2}$. Three independent experiments were realized to determine the lead concentration. The experimental standard deviation was determined to be $\pm 5 \%$.

\section{Results and Discussion}

\section{Characterization of the synthesized membranes by FTIR}

\section{Analysis}

The main features of this spectrum are an absorption band located around $1719 \mathrm{~cm}^{-1}$, which is attributed to stretching vibrations of the carbonyl group $(\mathrm{C}=0)$ of DOP plasticizer (Figure 2). Band detected at around $1583 \mathrm{~cm}^{-1}$ corresponds to the elongation vibrations of the $(\mathrm{C}=\mathrm{C})$ bond of the benzene groups. Bands at 1236 and $1017 \mathrm{~cm}^{-1}$ correspond to the stretching modes of asymmetric and symmetric $\mathrm{C}-\mathrm{O}-\mathrm{C}$ of $\mathrm{PSu}$ respectively. Three other bands characteristic of the elongation vibrations bonds of $\mathrm{SO}_{2}, \mathrm{~S}=0$ and C-S detected at $1301 \mathrm{~cm}^{-1}, 1104 \mathrm{~cm}^{-1}$ and $553 \mathrm{~cm}^{-1}$ respectively were also observed. The FTIR spectrum of the membrane 2 (CTA + DOP) (Figure 3) showed two bands at 2956 and $2863 \mathrm{~cm}^{-1}$ attributed to elongation vibrations of the asymmetric and symmetric $\mathrm{C}-\mathrm{H}$ bonds respectively. The presence of carbonyl groups of the ester function of CTA was evidenced by the existence of a band located at around $1728 \mathrm{~cm}^{-1}$. The acetate groups (COO-) were detected at $1574 \mathrm{~cm}^{-1}$. We also noted that the CTA absorbed at around 1221 and $1034 \mathrm{~cm}^{-1}$ characterizing the asymmetric and symmetric elongation vibrations of (C-O-C) groups.

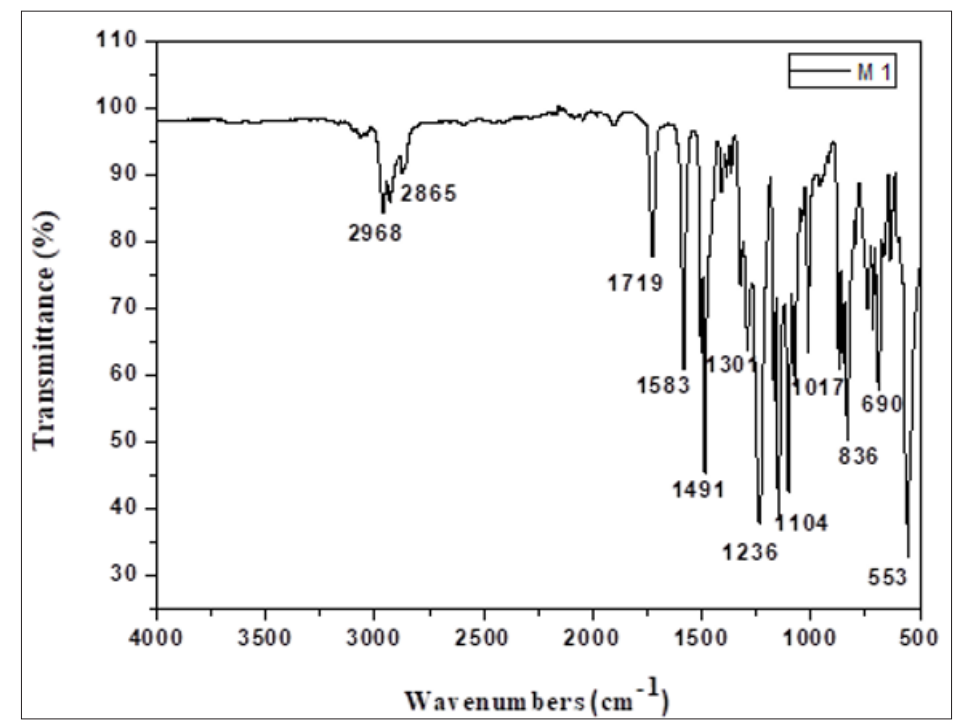

Figure 2: FTIR spectrum of the synthesized polymeric membrane (PSu+ DOP).

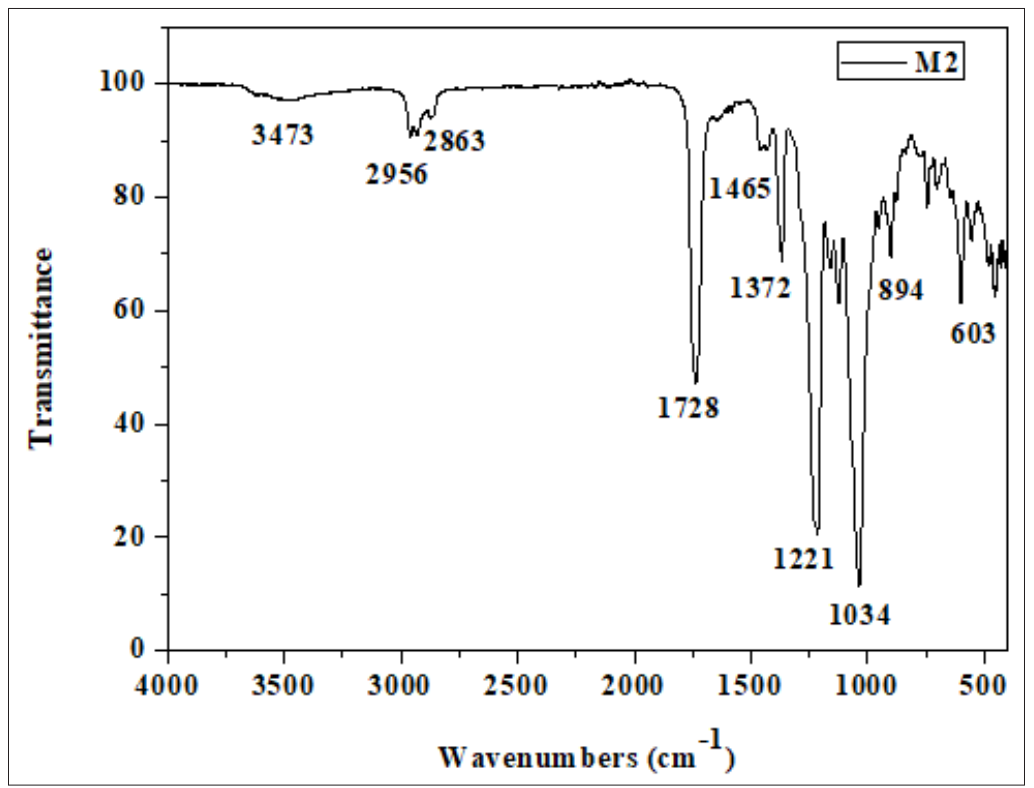

Figure 3: FTIR spectrum of the synthesized polymeric membrane (CTA + DOP). 
The main feature of this spectrum is an absorption band located around $1739 \mathrm{~cm}^{-1}$, which is attributed to stretching vibrations of the carbonyl group. Bands at 1232 and $1044 \mathrm{~cm}^{-1}$ correspond to the stretching modes of C-O-C bonds of CTA. Less intense bands at 2957 and $2863 \mathrm{~cm}^{-1}$ are attributed to $\mathrm{C}-\mathrm{H}$ bonds and the wide band detected in the $3492 \mathrm{~cm}^{-1}$ region is attributed to the $\mathrm{O}-\mathrm{H}$ bonds (Figure 4). Two other bands characteristic of the elongation vibrations bonds of $\mathrm{SO}_{2}$ and C-S detected at 1372 and $557 \mathrm{~cm}^{-1}$ respectively confirmed the presence of PSu. The FTIR spectrum of the membrane 4 (PSu + CTA + DOP + D2EHPA) Figure 5 showed two bands at 2957 and $2863 \mathrm{~cm}^{-1}$ attributed to elongation vibrations of the asymmetric and symmetric $\mathrm{C}-\mathrm{H}$ bonds respectively. The presence of carbonyl groups of the ester function of CTA was evidenced by the existence of a band located at around $1730 \mathrm{~cm}^{-1}$. The acetate groups (COO-) were detected at $1589 \mathrm{~cm}^{-1}$. We also noted that the CTA absorbed at around 1243 and $1018 \mathrm{~cm}^{-1}$ characterizing the asymmetric and symmetric elongation vibrations of ( $\mathrm{C}-\mathrm{O}-\mathrm{C})$ groups. Two other bands characteristic of the elongation vibrations bonds of $\mathrm{SO}_{2}$ and C-S detected at 1373 and $529 \mathrm{~cm}^{-1}$ respectively confirmed the presence of PSu.

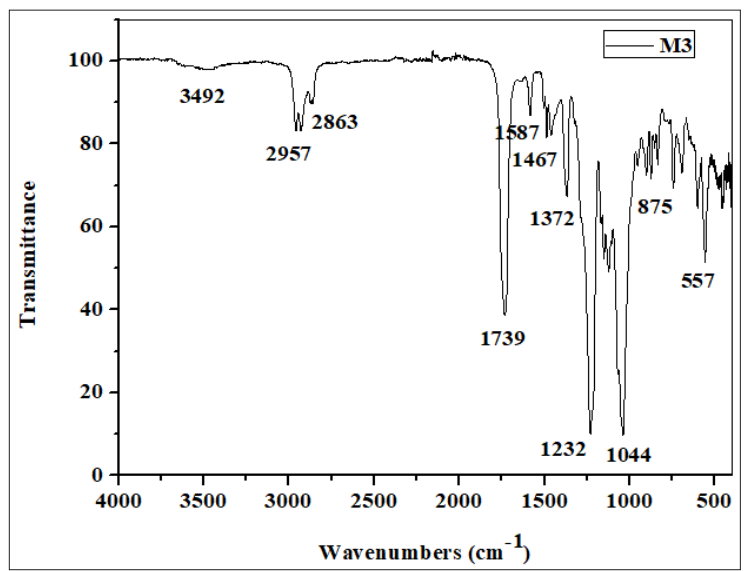

Figure 4: FTIR spectrum of the synthesized polymeric membrane (PSu + CTA + DOP).
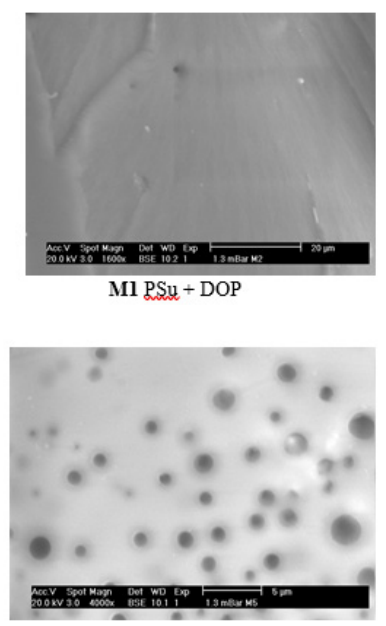

M3 PSu+CTA + DOP

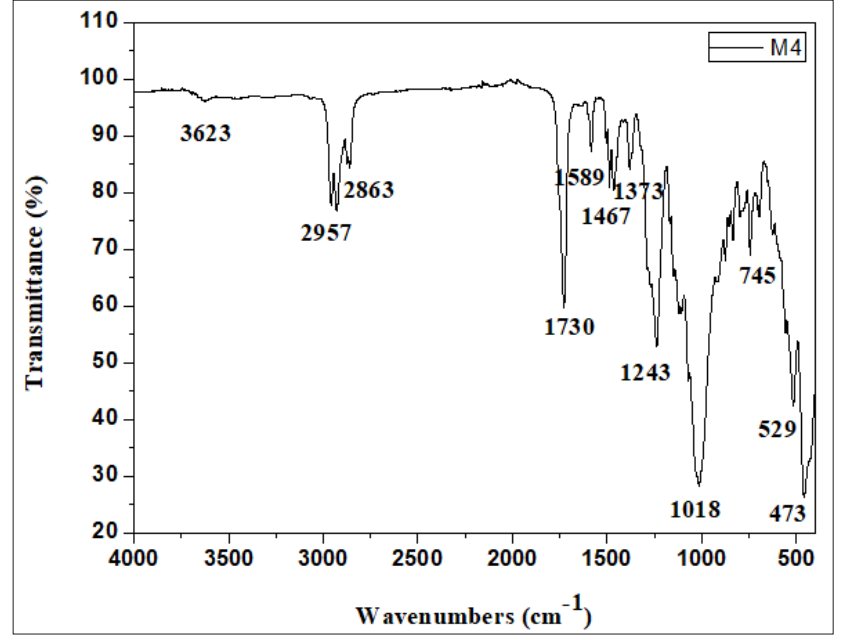

Figure 5: FTIR spectrum of the synthesized polymeric membrane (PSu + CTA + DOP + D2EHPA).

\section{Characterization by SEM}

One important aspect of PIMs is the microstructure of the membrane materials, which determines the distribution of carrier in the polymer matrix and ultimately affects the membrane transport efficiency. Consequently, considerable research effort has been devoted to clarifying this issue. SEM provides excellent qualitative information (dense or porous membranes) and quantitative capability in measuring important subsurface features, such as porosity and layer thickness. The morphology of the PSu membrane (view of surface) shows that this membrane constituted by only one polymer and plasticized by DOP presents a dense and homogeneous structure. On the other hand, the (CTA+DOP), (PSu+CTA+DOP) and $(\mathrm{PSu}+\mathrm{CTA}+\mathrm{DOP}+\mathrm{D} 2 \mathrm{EHPA})$ membranes display a porous structure, the distribution of the pores is nearly uniform. This is probably due to the fact that the D2EHPA increases the spaces or pores which may be generated after the interactions developed between the different compounds of the membrane. Figure 6 shows the morphology of the different elaborated membranes before cationic transport.
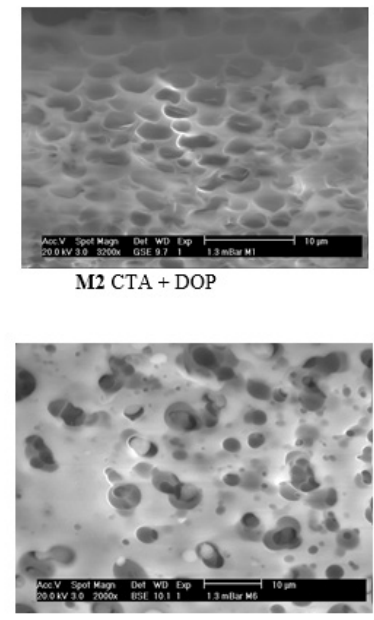

$\mathbf{M} 4 \mathrm{PSu}+\mathrm{CTA}+\mathrm{DOP}+\mathrm{D} 2 \mathrm{EHPA}$

Figure 6: SEM images for all synthesized membranes. 


\section{Characterization of the synthesized membranes by TGA}

\section{Analysis}

As it can be seen from Figures 7-10, all synthesized membranes exhibited a good thermal stability until $180^{\circ} \mathrm{C}$. Firstly, (PSu+DOP) and (CTA+DOP) membranes decompose in two steps. However, (PSu+CTA+DOP) membrane decomposes in three steps process. The first step (32\%) occurring at $300{ }^{\circ} \mathrm{C}$ represents the thermal degradation of the plasticizer DOP. The second one starting at around $340-390^{\circ} \mathrm{C}$, represents the main thermal degradation of the polymeric chains of CTA. The third step started at $520^{\circ} \mathrm{C}$ corresponds to the PSu degradation. Nevertheless, (PSu+CTA+DOP+D2EHPA) membranes are thermally degraded in two steps. The first one at $193{ }^{\circ} \mathrm{C}-320{ }^{\circ} \mathrm{C}$ represents the volatilization of the mixture (DOP, D2EHPA and CTA). The second step at $500{ }^{\circ} \mathrm{C}$, represents a degradation of the PSu polymer chains. Based on these figures, we can confirm that all the synthesized membranes exhibit a good thermal stability.

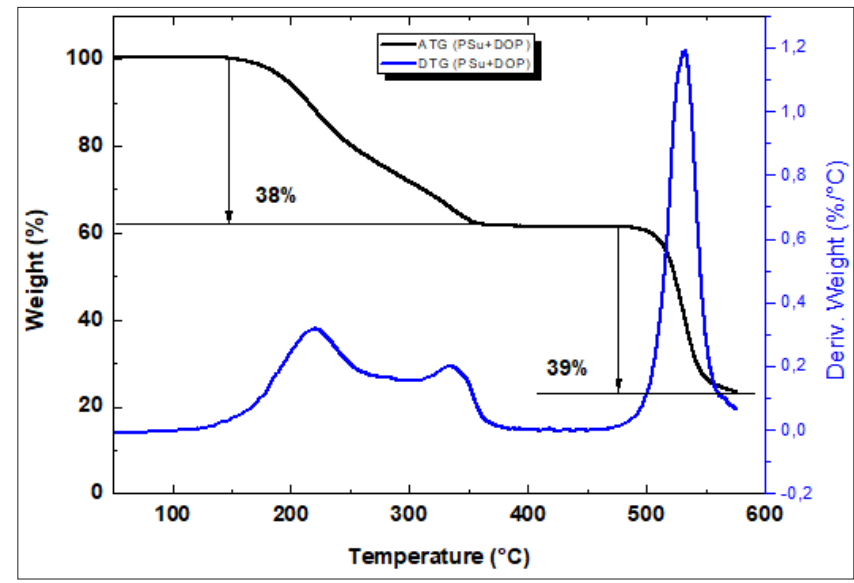

Figure 7: TGA and dTGA of (PSu + DOP) membrane.

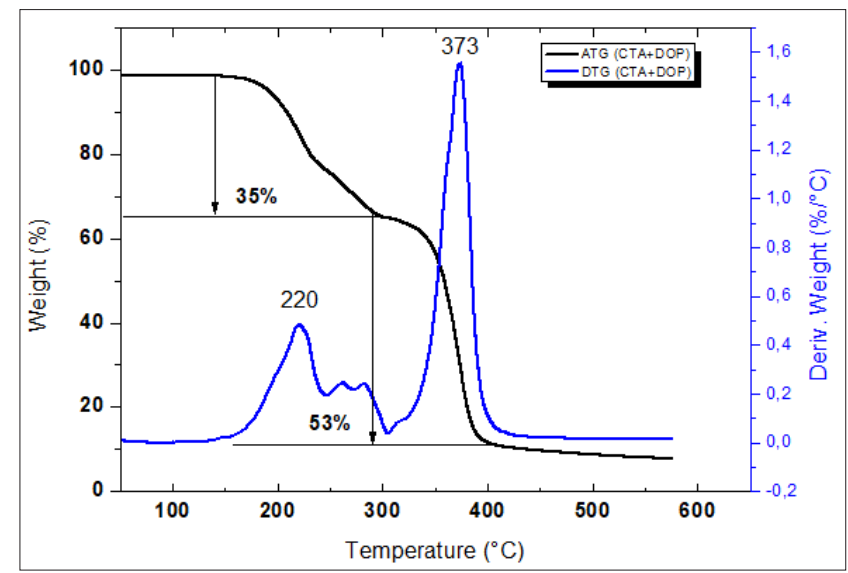

Figure 8: TGA and dTGA of (CTA + DOP) membrane.

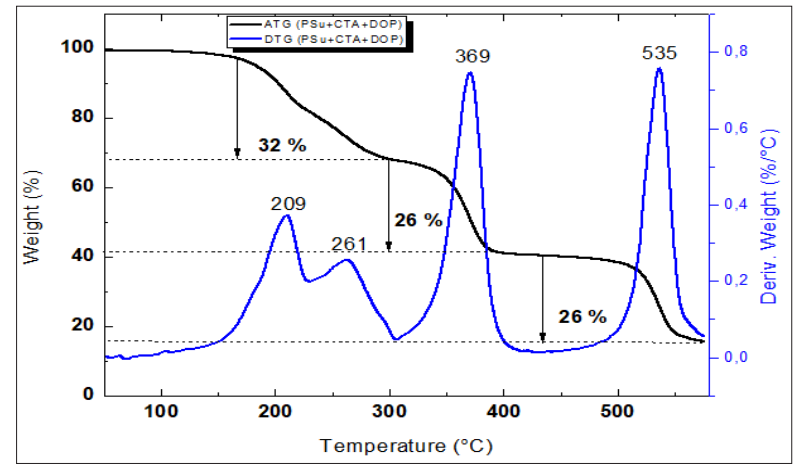

Figure 9: TGA and dTGA of (PSu + CTA + DOP) membrane.

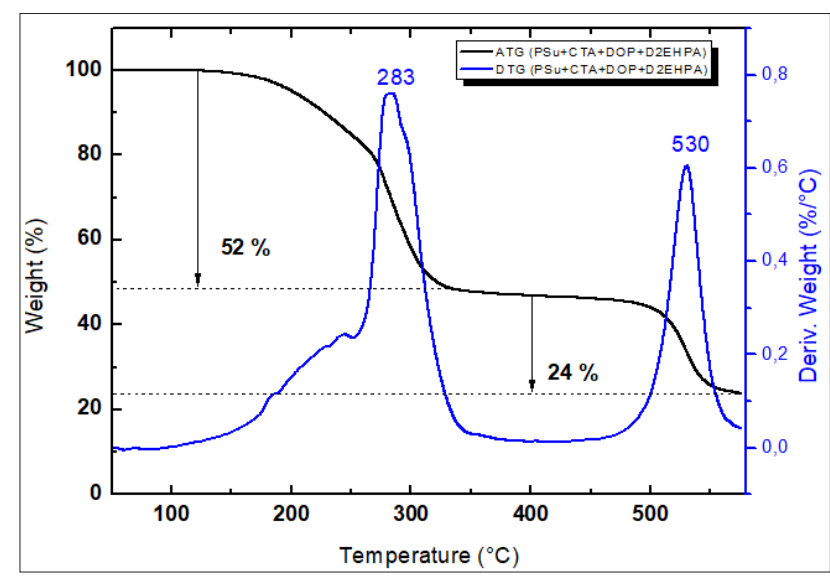

Figure 10: TGA and dTGA of (PSu + CTA + DOP + D2EHPA) membrane.

\section{XRD analysis}

Figure 11 shows the XRD patterns of the synthesized membranes: (PSu +DOP), (CTA + DOP), (PSu + CTA + DOP) and $(\mathrm{PSu}+\mathrm{CTA}+\mathrm{DOP}+\mathrm{D} 2 \mathrm{EHPA})$ membranes. Based on these figures, we can observe that all synthesized membranes present a single maximum located at approximately $20^{\circ}$ found in all polymers and corresponds to the Van deer Waals halo. Thus, the systems constituted by the mixture of Polymer1 + Plasticizer + Polymer2 are amorphous and do not give any diffraction peak. On the other hand, the absence of crystallization within the membrane permits us to eliminate the mechanism of ions transfer by successive jumps between agent complexing sites in 3D assembled state. Thus, the systems constituted by the mixture of polymer + plasticizer + carrier are amorphous and do not give any diffraction peak. On the other hand, the absence of crystallization within the membrane permits to eliminate the mechanism of ions transfer by successive jumps between agent complexing sites in 3D assembled state. The theory of fixed-site jumping has been described by Cussler EL et al. \& Noble RD [34,35]. 


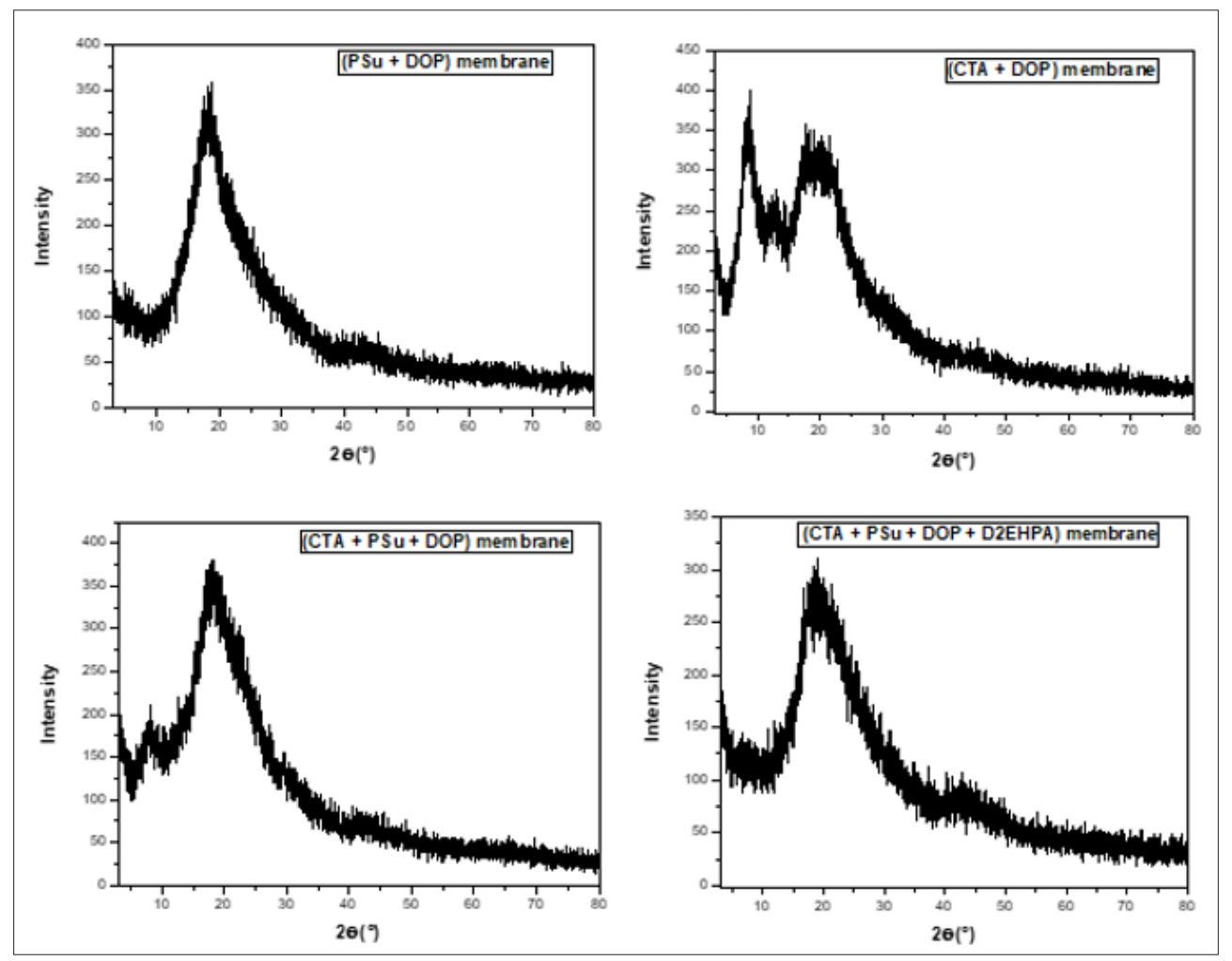

Figure 11: X-Ray diffractogram of all synthesized membranes.

\section{Contact angle measurements}

A comparison of the hydrophilicity of the synthesized composite membranes by the water contact angles is shown in Table 1. Compared with $(\mathrm{PSu}+\mathrm{DOP})$ control membrane $\left(74.9 \pm 0.3^{\circ}\right)$, the water contact angles of the elaborated membranes were found to increase evidently (07\%). Lower water contact angles correspond to more hydrophilic surfaces. The average contact angles of PSu/ CTA/DOP/D2EHPA membrane are lower than the control PSu/ DOP and CTA/DOP membranes. The improved hydrophilicity of the synthesized membranes can be attributed to the presence of hydrophilic CTA arising from the hydroxyl functional groups on their surface. At the same time, a decrease of the average contact angles indicates a successful incorporation of the carrier (D2EHPA) into the polymer matrix. Contact angle measurements at the surface were determined using ultrapure water. As the carriers' molecules are hydrophilic, the location of the carrier at the surface of the PSu/ CTA modified membrane should modify the contact angle, which is a parameter indicative of the wetting character of a material $\left(\theta=75^{\circ}\right.$ in the case of PSu membrane and $\theta=\sim 69^{\circ}$ in the case of $(\mathrm{PSu}+\mathrm{CTA}+\mathrm{DOP})$ and (PSu+CTA+DOP+D2EHPA) membranes.

Table 1: Average contact angle of the synthesized composite membranes.

\begin{tabular}{|c|c|c|}
\hline Membrane & Contact Angle ${ }^{(}{ }^{\circ}$ ) & Standard Deviation \\
\hline PSu & 86.28 & 0.3 \\
\hline CTA & 46.37 & 0.1 \\
\hline PSu + DOP & 74.9 & 0.3 \\
\hline
\end{tabular}

\begin{tabular}{|c|c|c|}
\hline CTA + DOP & 66.9 & 0.1 \\
\hline PSu + CTA + DOP & 69.7 & 0.4 \\
\hline PSu + CTA + DOP + D2EHPA & 68.2 & 0.2 \\
\hline
\end{tabular}

\section{Lead (II) and cadmium (II) transport experiments}

The porous, homogeneous and mechanically resistant membranes were used in the transport experiments: (CTA+DOP), $(\mathrm{PSu}+\mathrm{CTA}+\mathrm{DOP})$ and $(\mathrm{PSu}+\mathrm{CTA}+\mathrm{DOP}+\mathrm{D} 2 \mathrm{EHPA})$ membranes in comparison with (PSu+DOP) dense membrane. Figures 12 \& 13 represent the evolution of the concentration of $\mathrm{Pb}^{2+}$ and $\mathrm{Cd}^{2+}$ respectively in the feed and strip compartments as a function of time using the different synthesized membranes. We note that the quantities of $\mathrm{Cd}(\mathrm{II})$ and $\mathrm{Pb}(\mathrm{II})$ ions decrease strongly in the feed compartment by passing from the membrane containing only one polymer to the membrane containing two polymers, plasticizer and carrier thus confirming that the transport of metallic ions is an active transport, where both carrier and plasticizer play an important role in the process. The increase of the two ions concentrations in the strip compartment using PSu + CTA + DOP and PSu + CTA + DOP + D2EHPA membranes shows that the introduction of the plasticizer and carrier facilitated the transport of ions. These results are in accordance with the literature [36-38] and show that the membrane containing D2EHPA as carrier is the one which gives the highest mass fluxes of lead and cadmium ions. Furthermore, the fluxes obtained with the membrane containing only polymer and plasticizer are slightly lower than that obtained using the modified membrane with carrier. 


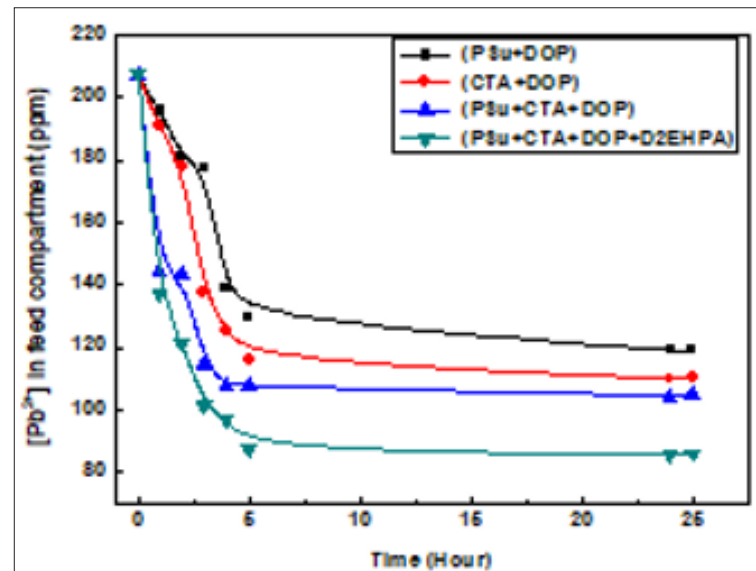

a)

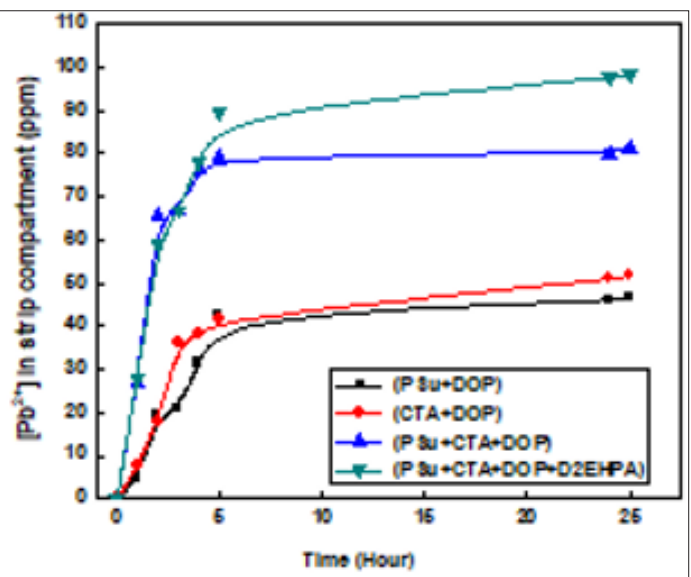

b)

Figure 12: Evolution of the concentration of $\mathrm{Pb}(\mathrm{II})$ in feed (a) and strip (b) compartments versus time. $\left[\mathrm{Pb}^{2+}\right] 0$ in the feed phase is fixed at $10^{-3} \mathrm{M}$.

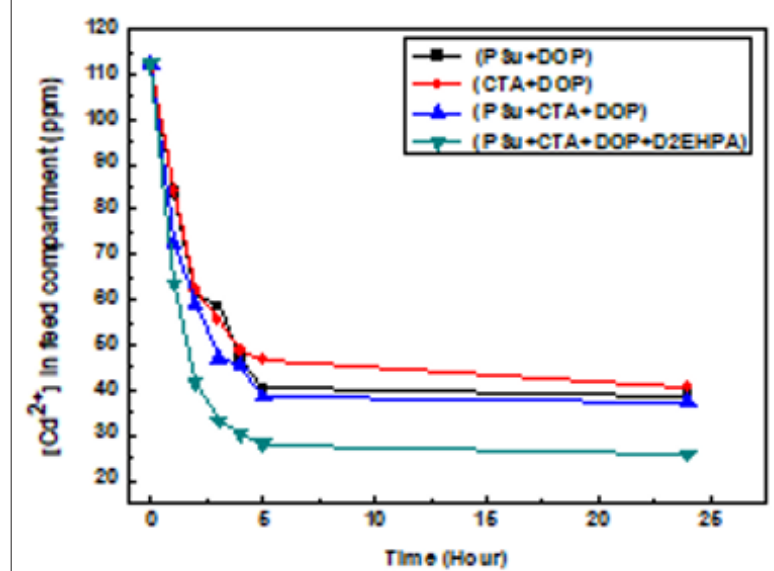

a)

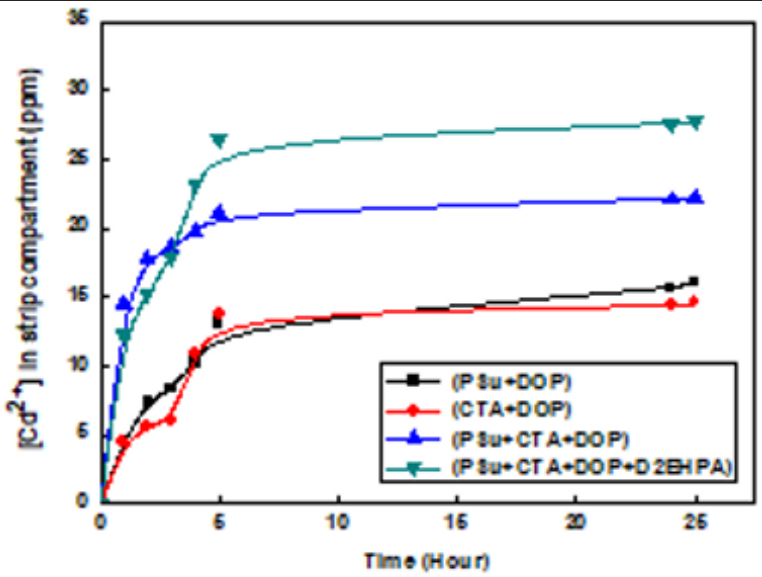

b)

Figure 13: Evolution of the concentration of $\mathrm{Cd}$ (II) in feed (a) and strip (b) compartments versus time. [ $\left.\mathrm{Cd}^{2+}\right] 0$ in the feed phase is fixed at $10^{-3} \mathrm{M}$.

\section{Conclusion}

In this work, we synthesized a new type of polymeric membranes using a mixture of polymers and prepared by solution casting followed by solvent evaporation. Membranes were successfully synthesized using two polymers (CTA and PSu) and plasticized by DOP. D2EHPA is used as selective mobile carrier. These polymers + plasticizer + carrier membranes were characterized using physical methods like Fourier transform infrared spectroscopy, X-ray diffraction, thermal analysis and scanning electron microscopy. All the synthesized membranes had amorphous structure with any diffraction peak. It can be due to the absence of crystallization within the membrane. The degradation of the membranes occurred via a two or three step process with the main loss starting at 180 ${ }^{\circ} \mathrm{C}$ due to the thermal degradation of the plasticizer. This result confirmed that all the synthesized membranes exhibited good thermal stability. The SEM observation of membranes revealed a dense or porous and homogeneous structure. Further analyses of membrane surface properties were performed by means of contact angle measurements. This technique allowed us, firstly, to monitor the effect of the plasticizer on the membrane surface properties, and second, to see the effect of the addition of the carrier in the polymeric mixture. A study of the transport across a polymer inclusion membrane has shown that the lead and cadmium transport efficiency was increased using D2EHPA as acidic carrier.

\section{References}

1. Kolev SD, Babab Y, Cattrall RW, Tasaki T, Pereira N, et al. (2009) Solid phase extraction of zinc (II) using a PVC-based polymer inclusion membrane with di(2-Ethylhexyl) phosphoric acid (D2EHPA) as the Carrier. Talanta 78(3): 795-799. 
2. Paugam MF, Buffle J (1998) Comparison of carrier-facilitated copper(II) ion transport mechanisms in a supported liquid membrane and in a plasticized cellulose triacetate membrane. Journal of Membrane Science 147(2): 207-215.

3. Bensaadi S, Arous O, Kerdjoudj H, Amara M (2016) Evaluating molecular weight of PVP on characteristics of CTA membrane dialysis. Journal of Environmental Chemical Engineering 4(2): 1545-1554.

4. Ulewicz M, Lenarcik ER (2012) Application of supported and polymer membrane with 1 decyl-2-methylimidazole for separation of transition metal ions. Physicochem Probl Miner Process 48(1): 91-102.

5. Akhond M, Shamsipur M (1996) Specific uphill transport of Cd2C ion by a cooperative carrier composed of containing aza-18-crown-6 and palmitic acid. Journal of Membrane Science 117: 221-228.

6. Rosen SL (1993) Fundamental principles of polymeric materials, John Wiley \& Sons, New York, USA.

7. Senichev VY, Tereshatov VV (2004) Influence of plasticizers on the glass transition temperature of polymers. In: Wypych G (Ed.), Handbook of Plasticizers, Chem Tec Publishing, New York, USA, pp. 218-227.

8. Ammi Said A, Arous O, Yahia Cherif S, Berbar Y, Amara M, et al. (2019) Surfactant based modifcation of sodic Algerian illite clay for the preparation of polymeric membranes: Application for separation of iron and zinc ions from aqueous solutions. Polymer Bulletin 76(7): 36593676.

9. Abdellaoui N, Laoui FM, Cerbah H, Arous O (2018) Preparation of poly (N,N-dimethylaminoethyl methacrylate)(PDAEM) membranes: Application for water purification. Journal of Applied Polymer Science 135(32): 46592.

10. Arous 0, Kerdjoudj H, Seta P (2004) Comparison of carrier-facilitated silver (I) and copper (II) ions transport mechanisms in a supported liquid membrane and in a plasticized cellulose triacetate membrane. Journal of Membrane Science 241(2): 177-185.

11. Bayou N, Arous O, Amara M, Kerdjoudj H (2010) Elaboration and characterisation of plasticized cellulose triacetate membrane containing trioctylphosphineoxyde (TOPO): Application to the transport of uranium and molybdenum ions. Comptes Rendus Chimie. 13(11): 1370-1376.

12. Zioui, D, Arous O, Mameri N, Kerdjoudj H, Sebastian MS, et al. (2017) Membranes based on polymer miscibility for selective transport and separation of metallic ions. Journal of Hazardous Materials 336: 188194.

13. Vázquez, MI, Romero V, Fontàs C, Anticó E, Benavente J (2014) Polymer inclusion membranes (PIMs) with the ionic liquid (IL) aliquat 336 as extractant: Effect of base polymer and IL concentration on their physicalchemical and elastic characteristics. Journal of Membrane Science 455: 312-319.

14. Almeida MS, Silva AL, Cattrall RW, Kolev SD (2015) A study of the ammonium ion extraction properties of polymer inclusion membranes containing commercial dinonylnaphthalene sulfonic acid. Journal of Membrane Science 478: 155-162.

15. Arous O, Amara M, Trari M, Bouguelia A, Kerdjoudj H (2010) Cadmium (II) and lead (II) transport in a polymer inclusion membrane using tributyl phosphate as mobile carrier and $\mathrm{CuFeO}_{2}$ as a polarized photo electrode. Journal of Hazardous Materials 180(1-3): 493-498.

16. Ulewicz M, Tao JS, Biernat JF (2009) Selectivity of Pb(II) transport across polymer inclusion membranes doped with imidazole azothiacrown ethers. Journal of Membrane Science 344(1-2): 32-38.

17. Thunhorst KL, Noble RD, Bowman CN (1999) Properties of the transport of alkali metal salts through polymeric membranes containing benzo18-crown-6 crown ether functional groups. Journal of Membrane Science 156(2): 293-302.
18. Schow AJ, Peterson RT, Lamb JD (1996) Polymer inclusion membranes containing macrocyclic carriers for use in cation separations. Journal of Membrane Science 111(2): 291-295.

19. Fyles T (1990) Polymer membrane for proton driven ion transport, US Patent 4,906,376.

20. Arena G, Contino A, Magri A, Sciotto D, Lamb JD (1998) Selective transport of cesium and strontium ions through polymer inclusion membranes containing calix-arenes as carriers. Supramolecular Chemistry 10(2): 105-115.

21. Tayeb R, Fontas C, Dhahbi M, Tingry S, Seta P (2005) Cd(II) transport across supported liquid membranes (SLM) and polymeric plasticized membranes (PPM) mediated by Lasalocid A. Separation and Purification Technology 42(2): 189-193.

22. Aguilar JC, Castellanos MS, Rodriguez ME, Gyves J (2001) Cd(II) and $\mathrm{Pb}(\mathrm{II})$ Extraction and transport modeling in SLM and PIM systems using kelex 100 as carrier. Journal of Membrane Science 190(1): 107-118.

23. Lacan P, Guizard C, Gall PL, Wettling D, Cot L (1995) Facilitated transport of ions through fixed-site carrier membranes derived from hybrid organic-inorganic materials. Journal of Membrane Science 100(2): 99109.

24. Kang YS, Hong JM, Jang J, Kim UY (1996) Analysis of facilitated transport in solid membranes with fixed site carriers .1. Single RC circuit model. Journal of Membrane Science 109(2): 149-157.

25. Hong JM, Kang S, Jang J, Kim UY (1996) Analysis of facilitated transport in polymeric membrane with fixed site carrier 2 . Series RC circuit model. Journal of Membrane Science 109(2): 159-163.

26. McBride JW, Izatt RM, Lamb JD, Christensen JJ (1984) Inclusion Compounds III, Academic Press, London, pp: 571-628.

27. Hayashita T, Sawano H, Higuchi T, Indo M, Hiratani K, et al. (1999) Molecular design of acyclic polyether dicarboxylic acids possessing pseudo-18-crown-6 frameworks for selective Lead (II) extraction. Anal Chem 71(4): 791-795.

28. Ohto K, Fujimoto Y, Inoue K (1999) Stepwise extraction of two lead ions with a single molecule of calix[4]arene tetracarboxylic acid. Analytica Chimica Acta 387(1): 61-69.

29. Costero AM, Monrabal E, Sanjuan F, Manez RM, Tosta MP, et al. (1999) Redox-active aza-crown ethers derived from biphenyl. Electrochemical and solution studies of complexation. Tetrahedron 55(52): 1514115150.

30. Parr J (1997) Some recent coordination chemistry of lead (II). Polyhedron 16(4): 551-566.

31. Sugiura M, Kikkawa M, Urita S (1987) Effect of plasticizer on carrier mediated transport of zinc ion through cellulose triacetate membranes. Separation Science and Technology 22(11): 2263-2268.

32. Sugiura M, Kikkawa M, Urita S (1989) Carrier-mediated transport of rare earth ions through cellulose triacetate membranes. Journal of Membrane Science 42(1-2): 47-55.

33. Sugiura M (1993) Effect of quaternary ammonium salts on carriermediated transport of lanthanide ions through cellulose triacetate membranes. Separation Science and Technology 28(7): 1453-1463.

34. Cussler EL, Rutherford A, Brown A (1989) On the limits of facilitated diffusion. Journal of Membrane Science 43(2-3): 149-164.

35. Noble RD (1992) Generalized microscopic mechanism of facilitated transport in fixed site carrier membranes. Journal of Membrane Science 75(1-2): 121-129.

36. Ulewicz M, Lesinska U, Bochenska M, Walkowiak W (2007) Facilitated transport of $\mathrm{Zn}(\mathrm{II}), \mathrm{Cd}(\mathrm{II})$ and $\mathrm{Pb}(\mathrm{II})$ ions through polymer inclusion 
membranes with calix[4]-crown-6 derivatives. Separation and Purification Technology 54(3): 299-305.

37. Lenarcik ER, Ulewicz M (2012) Selective transport of Cu(II) across a polymer inclusion membrane with 1-alkylimidazole from nitrate solutions. Separation Science and Technology 47(8): 1113-1118.
38. Nghiem LD, Mornane P, Potter ID, Perera JM, Cattrall RW, et al. (2006) Extraction and transport of metal ions and small organic compounds using polymer inclusion membranes (PIMs). Journal of Membrane Science 281(1-2): 7-41.

For possible submissions Click below: 